Information

Article https://dx.doi.org/10.4314/iijikm.v9i3.9

\section{Relationship between Patients' Access to Health Information and Coping with Chronic Diseases}

Ebele N. Anyaoku

Nnamdi Azikiwe University

Nnewi, Nigeria
Impact

Information Impact: Journal

of information and

knowledge management

2018, Vol. 9 (3) Pg. 117-131

ISSN: $2141-4297$ (print)

ISSN: 2360 - 994X (e-version)

\begin{abstract}
The research examined the association between patients' demographics, access to health information on coping and self-efficacy in managing chronic illness. This is a correlation study. The population for this study is seven hundred and eighty-four patients with chronic diseases in two Federal Government Teaching Hospitals in South-East, Nigeria. A Questionnaire and a Coping with Chronic Diseases Self-Efficacy Scale were instruments for data collection. Correlation analysis shows that access to coping information was positively and significantly correlated with self-efficacy in managing chronic diseases. Multiple Regression suggests that disease type was the only patient characteristics significantly associated with self-efficacy when patients have access to coping information. The study conclude that the significant associations indicate that health information can enable patients develop self-efficacy for coping with chronic diseases. Hospital administrators and all stakeholders involved in health care should create an enabling environment for information sharing and flow to patients with chronic diseases. Librarians should play some roles in creating access to health information for patients with chronic diseases through developing and promoting consumer health information resources.
\end{abstract}

Keywords: Health information, Coping; Self-efficacy, Chronic diseases; Selfmanagement; Consumer health information service.

\title{
Introduction
}

Disease conditions such as arthritis, hypertension, diabetes, heart diseases, cancer, HIV and AIDS are tagged chronic diseases because they require extended care sometimes for the life span of the individual. Living with a chronic disease and sometimes with multiple chronic diseases can be an all-encompassing challenge which can negatively affect an individual physically and emotionally. They may present with physical impairments, pain, emotional trauma of anxiety, and depression. If patients will meet the challenges of lifelong illnesses in their daily lives, they need to cope effectively with the physical discomfort, psychological distress, adherence to medication and financial drain associated with living with these diseases. 
Snyder (199) defined coping as a response aimed at diminishing the physical, emotional and psychological burden that is linked to stressful life events and daily hassles. Individuals who are able to cope effectively and mobilize resources are more successful in managing stress and achieving more stable outcome. Coping mechanisms are learned and developed over time. Individual use them to manage, tolerate, or reduce stress associated with significant life events and to attempt to restore psychological equilibrium after a stressful or traumatic event (Falvo, 2013).

Self-efficacy has been defined as "people's beliefs about their capabilities to produce designated levels of performance that exercise influence over events that affect their lives. Selfefficacy beliefs determine how people feel, think, motivate themselves and behave. The concept of self-efficacy is based on Social Cognitive Theory, which proposes that human functioning is viewed as the product of a dynamic interplay of personal, behavioural, and environmental influences (Wood \& Bandura, 1997). Self-efficacy in this study has to do with patient's individual's confidence to undertake various self-management behaviours. This means patients' confidence that they can cope with the illness in their daily lives and adhere to requisite treatment.

\section{Health information and coping with chronic diseases}

To cope effectively, people living with chronic diseases need to understand the implications on their health, and learn skills to manage the day to day self-care requirements and challenges of living with the diseases. As noted by Institute of Medicine (2001) patients with chronic diseases are at high risk of developing serious and costly complications if not well informed on how to manage their conditions on a daily basis. Health information is any information used to help make an informed health-related decision or to inform oneself of healthrelated issues (Department of health and children, nd). Providing access to information is one way to helping the patient discover and develop the inherent capacity to be responsible for one's own life (Ma, Warren, Phillips, \& Stanek, 2006). Brashers, Goldsmith, and Hsieh (2002) wrote that managing information is an important part of coping with illness and includes communicative and cognitive activities like seeking, avoiding, providing, appraising, and 
interpreting information. Equally, Tilly and Kulinski (2017) noted that educating adults about their chronic conditions and how to better manage them is important because of the physical, emotional, and financial strain on the individual, their family and friends, as well as the financial impact on the healthcare system.

Arora, Johnson, Gustafson, McTavish, et. al. (2002) in a study of barriers to information access, perceived health competence, and psychosocial health outcomes examined the relationship between breast cancer patients' experience of barriers to accessing health information and their psychosocial health outcomes. Regression analyses suggested that patients who reported greater difficulty in accessing needed information experienced lower emotional, functional, and poorer psychosocial health as well as lower perceptions of health competence. There are many potential sources of information for patients with chronic diseases that can enlighten them on how to cope with everyday living with chronic diseases. They include health professionals, print resources such as books, pamphlets, magazines, posters, and electronic sources such as the validated consumer health sites on the Internet. Many public and medical libraries also offer consumer health information resources and self-help books. Organized programmes such as self-management education programmes are also provided by health professionals to provide information and skills that will enable patients cope with symptoms, reduce stress, Manage medications, improve mood and other aspects of living with chronic diseases (Centers for Disease Control and Prevention, 2017).

In terms of information seeking, two groups of people were identified in the literature in relation to coping style. They are monitors and blunters. two main psychological coping styles for dealing with cancer and other health threats have been identified monitoring (attending to) or blunting (avoiding) potentially threatening information. Monitors will want access to all the information available on a topic, while blunters also known as information avoiders may prefer only one or two general items or none at all. Patients fare better (psychologically, behaviourally, and physiologically) when the information they receive about their medical condition is tailored to their own coping styles: generally those with a monitoring style tend to do better when given more information, and those with a blunting style do better with less information (Miller, 1995). 
This means that information for patient empowerment for self-care must be specific to the needs of the individual, and personality factors of the patients. Ankem (2006) wrote that although the benefits of possessing information are known, not all patients are alike in their need for information. Patient demographics (age, education, and gender), the situations they find themselves in during illness, and their psychological states can determine the need for and receptivity to disease-related information. The identification of these variables as they affect selfefficacy can help in proper tailoring of health information to achieve the expected benefits. The main purpose of the study was therefore to find out the association between patients' demographic variables, access to health information on coping and treatment and Self-efficacy in managing chronic diseases.

\section{Research Questions}

The Following questions guided the study

1. What are they coping information received by patients with chronic diseases?

2. What are patients' perceptions of self-efficacy in coping with chronic diseases?

3. What is the relationship between patients' access to coping information and patients' selfefficacy in managing chronic diseases?

\section{Hypotheses}

1. There is no significant relationship between patients' access to coping information and patients' self-efficacy in managing chronic diseases.

2. There is no significant relationship between patient's access to coping information and patient's self- efficacy in managing chronic diseases based on the patient's personal characteristics

\section{Methodology}

The study was carried out in two Federal Government Teaching Hospitals in Nigeria in south East Nigeria. They are University of Nigeria Teaching Hospital (UNTH) and Nnamdi Azikiwe University Teaching Hospital (NAUTH). Patients that participated in the study were those who are with the following chronic diseases: hypertension, Diabetes, Cancer, Kidney 
Disease, HIV and AIDS. The study was approved by the Ethics committee of both NAUTH and UNTH. A questionnaire was developed to solicit information on access to information, patients' self-efficacy. The questionnaire was face validated by two medical doctors from NAUTH and pretested on 15 patients in a Hospital in Anambra State. Access to coping information were measured using six items for each $(\alpha=.916)$ : Response options for the two information access variables were on a four-point scale: of (4) Much information (3) Some information (2) Little information, (1) No information. Self-efficacy for coping with chronic disease Scale: The Scale was developed based on the Validated Self-Efficacy for Managing Chronic Disease Scale, developed by Stanford Patient Education Research Center (nd). Self -efficacy was measured with five items Response option was a five-point scale from 'Completely confident', to 'Not confident'.The questionnaire and self-efficacy scale were submitted to the Medical Ethics Committee of the two institutions under study for approval. After due consideration for presence of ethical issues, the Ethics Committee of both institutions issued approval for distribution of the questionnaires to patients in their hospitals.

Questionnaires were hand administered to patients in the Medical Out-patient clinics, the Oncology Clinics, and the Retroviral Disease Clinics of the two hospitals. Research Assistants were trained to distribute the questionnaire and collect data from patients. One thousand and eighty questionnaires were distributed to the patients. Seven hundred and eighty-four usable questionnaires were obtained. This represents $73 \%$ of the distributed questionnaire. Two hundred and thirty-four copies were not properly completed while Sixty- two copies were not returned.

Descriptive statistics were calculated for level of access to coping and treatment information and Self-efficacy for coping with chronic disease. Bivariate correlations were computed and used to present the results of the correlations. All computations were done using SPSS Computer Software Package Version 17. Multiple Regression analysis was done to explore the predictive effect of socio-demographic variables on access to coping and treatment information and self- efficacy. Self-efficacy was used as the dependent variable. Coping information, demographic and disease profiles (gender, age, education, nature of illness, duration of illness, and duration of treatment in the teaching hospitals) were the independent variables. All analyses were computed using SPSS Computer Software Package Version 17. A test is statistically significant if it has a P-Value of less than 0.05 . The null hypothesis was therefore rejected. 


\section{Findings and discussions}

\section{Socio-demographic characteristics of study participants}

$61.2 \%$ of the respondents were females while $38.8 \%$ were males. For respondents age $36.7 \%$ were aged 45-64. And 36.6\% were aged 30-44 and 20\% were aged 65 and above. The least (10.7\%) age set was 18-29. For educational attainment, A greater percentage of the patients had Tertiary education (30.4\%), 28.8\% had Primary education, 26.9\% had secondary education and $13.9 \%$ had no formal education. For disease condition, majority 337 (43\%) of the respondents are HIV and AIDS patients. This is followed by hypertension 204 (26\%), diabetes 131(16.7\%), co-morbidity of hypertension and diabetes 52(6.6\%), cancer $40(5.1 \%)$ and kidney disease $20(2.6 \%)$.

\section{Coping Information Received by Patients with Chronic Diseases}

Mean scores indicate that patients received highest but moderate amount of information on coping with the symptoms of their illness (2.92) and how to control physical discomfort and pain if any (2.50); There is low access $(<2.50)$ recorded for other response items: Information on How to deal with emotions of anxiety and depression (2.49); Information on How to deal with Fatigue or tiredness (2.49) and What to do when emergency symptoms present (2.45) Respondents received the least and little information on How other people are coping with the illness i.e. peer support (2.31).

\section{Patients' Self-Efficacy in Coping with Chronic Diseases.}

Respondents were requested to indicate how confident or sure they are to keep the symptoms and discomforts of their illness from interfering with the things they do? Table 1 shows the percentage distribution and mean scores of respondents on their level of self-efficacy in coping with their illness. Mean score of the nine variables of self-efficacy shows that respondents rated their self-efficacy moderate (MS) $>3.00$ on managing symptoms, managing anxiety and depression, managing discomfort and pain, and managing fatigue.

Analysis of individual variables in terms of percentage distribution shows that a high percentage $516(65.9 \%)$ have high or complete confidence in their ability to manage anxiety and depression, and in managing symptoms 507 (64.7\%). More than half have high or complete confidence that they can manage discomfort and pain associated with chronic diseases 455 
(58\%), fatigue $413(52.7 \%)$ of their illness from interfering with the things they do. However, results in table 2 also shows that over 20\% (170) indicated that they have little or no confidence that they can manage the fatigue, emotions of anxiety, and depression, and the discomfort and pain of their illness from interfering with the things they do.

Table 1: Patients'Perception of Self-Efficacy in Coping with Chronic Diseases

$\begin{array}{llllll}\text { Not A little Moderately Highly Completely } & \text { Mean } & \text { Std. D }\end{array}$
Confident Confident Confident Confident Confident

\begin{tabular}{|c|c|c|c|c|c|c|c|}
\hline $\begin{array}{l}\text { Confidence } \\
\text { to manage } \\
\text { symptoms }\end{array}$ & $76(9.7 \%)$ & $\begin{array}{l}79 \\
(10.1 \%)\end{array}$ & $\begin{array}{l}122 \\
(15.6 \%)\end{array}$ & $\begin{array}{l}148 \\
(18.9 \%)\end{array}$ & $\begin{array}{l}359 \\
(45.8 \%)\end{array}$ & 3.80 & 1.36209 \\
\hline $\begin{array}{l}\text { Confidence } \\
\text { to manage } \\
\text { discomfort } \\
\text { and pain }\end{array}$ & $\begin{array}{l}99 \\
(12.6 \%)\end{array}$ & $\begin{array}{l}94 \\
(12.0 \%)\end{array}$ & $\begin{array}{l}136 \\
(17.3 \%)\end{array}$ & $\begin{array}{l}160 \\
(20.4 \%)\end{array}$ & $\begin{array}{l}295 \\
(37.6 \%)\end{array}$ & 3.58 & 1.41261 \\
\hline $\begin{array}{l}\text { Confidence } \\
\text { to manage } \\
\text { fatigue }\end{array}$ & $\begin{array}{l}115 \\
(14.7 \%)\end{array}$ & $\begin{array}{l}105 \\
(13.4 \%)\end{array}$ & $\begin{array}{l}151 \\
(19.3 \%)\end{array}$ & $\begin{array}{l}148 \\
(18.9 \%)\end{array}$ & $\begin{array}{l}265 \\
(33.8 \%)\end{array}$ & 3.44 & 1.43969 \\
\hline $\begin{array}{l}\text { Confidence } \\
\text { to manage } \\
\text { Anxiety }\end{array}$ & $\begin{array}{l}79 \\
(10.1 \%)\end{array}$ & $\begin{array}{l}91 \\
(11.6 \%)\end{array}$ & $98(12.5 \%)$ & $\begin{array}{l}173 \\
(22.1 \%)\end{array}$ & $\begin{array}{l}343 \\
(43.8 \%)\end{array}$ & 3.78 & 1.37362 \\
\hline $\begin{array}{l}\text { Confidence } \\
\text { in keeping } \\
\text { appointments } \\
\text { and judging } \\
\text { when to see a } \\
\text { doctor }\end{array}$ & $57(7.3 \%)$ & $52(6.6 \%)$ & $56(7.1 \%)$ & $\begin{array}{l}142 \\
(18.1 \%)\end{array}$ & $\begin{array}{l}477 \\
(60.8 \%)\end{array}$ & 4.19 & 1.25172 \\
\hline $\begin{array}{l}\text { Confidence } \\
\text { to take drugs } \\
\text { appropriately }\end{array}$ & $14(1.8 \%)$ & $21(2.7 \%)$ & $60(7.7 \%)$ & $\begin{array}{l}134 \\
(17.1 \%)\end{array}$ & $\begin{array}{l}555 \\
(70.8 \%)\end{array}$ & 4.52 & .88 \\
\hline
\end{tabular}

Very High self-efficacy (VHS) 4.56 - 5.00, High self-efficacy (HS) 4.00 - 4.55, Moderate selfefficacy (MS) 3.00 - 3.99, Low self-efficacy (LS) 2.99 - 2.00, Very Low self-efficacy (VLS) 1.99- 1.00 


\section{Correlation}

Result of Bivariate correlations computed for Research Question 3 and Hypothesis 1 is shown in Table 2 .

Table 2: Correlation Matrix of Access to Coping Information and Self-Efficacy

$$
\text { 1. 2. 3. } 4.4 \text { 6. } \quad \text { 6. Mean Std. }
$$

Dev

\begin{tabular}{|c|c|c|c|c|c|c|c|c|c|c|}
\hline 1. & Self-Efficacy & 1 & $.433^{*}$ & $.375^{*}$ & $.429^{*}$ & $.426^{*}$ & $.421^{*}$ & $.380^{*}$ & & \\
\hline 2. & $\begin{array}{l}\text { How to coping with } \\
\text { symptoms }\end{array}$ & $.433^{*}$ & 1 & & & & & & 2.92 & 1.16 \\
\hline 3. & $\begin{array}{l}\text { Control of discomfort } \\
\text { and pain }\end{array}$ & $.375^{*}$ & $.561^{*}$ & 1 & & & & & 2.50 & 1.25 \\
\hline 4. & $\begin{array}{l}\text { Dealing with anxiety } \\
\text { and depression }\end{array}$ & $.429^{*}$ & $.577^{*}$ & $.631^{*}$ & 1 & & & & 2.49 & 1.26 \\
\hline 5. & $\begin{array}{l}\text { Dealing with fatigue } \\
\text { and tiredness }\end{array}$ & $.426^{*}$ & $.532^{*}$ & $.610^{*}$ & $.692^{*}$ & 1 & & & 2.49 & 1.26 \\
\hline 6. & $\begin{array}{l}\text { What to do in } \\
\text { emergency }\end{array}$ & $.421^{*}$ & $.532^{*}$ & $.583^{*}$ & $.587^{*}$ & $.628^{*}$ & 1 & & 2.45 & 1.24 \\
\hline 7. & How others are coping & $.380^{*}$ & $.467^{*}$ & $.444^{*}$ & $.487^{*}$ & $.490^{*}$ & $.541^{*}$ & 1 & 2.31 & 1.27 \\
\hline
\end{tabular}

*Significant at $\mathrm{P}<0.05$

Table 2 shows the correlation between self-efficacy and all six variables of access to coping information. The result shows that self-efficacy is positively and significantly correlated with all the variables of coping information $(\mathrm{p}<0.05)$. Patients access to information on coping with symptoms has the highest correlation with self-efficacy showing a moderately positive correlation $(\mathrm{r}=.433)$. Coping with discomfort and pain $(\mathrm{r}=.375)$, are positively but lowly correlated with self-efficacy. Based on the significant correlation $(\mathrm{p}<0.05)$ between all six variables of coping information, the null hypothesis of no significant relationship between patients' access to coping information and patients' self-efficacy in managing chronic diseases is therefore rejected. Higher access to coping information was associated with higher self-efficacy. 


\section{Association between Patients' Demographic and Disease Variables, Access to}

\section{Coping Information and Self-efficacy}

H2: There is no significant relationship between patient's access to coping information and patient's self-efficacy in managing chronic diseases based on the patient's personal characteristics.

\section{Multivariate Regression}

Multivariate Regression Analysis was computed to explore the association of patient characteristics to the significant relationship between access to coping information and selfefficacy. In this analysis, self-efficacy was used as dependent variable, while access to coping information, gender, age, education, disease type, duration of illness and duration of treatment were used as independent variables. The results are shown in Table 3.

Table 3: Association between Patients' Demographic and Disease Variables, Access to Coping Information and Self-efficacy

\begin{tabular}{|c|c|c|c|c|c|}
\hline & $\mathrm{R}^{2}$ & $\mathrm{~F}^{*}$ & Beta & SE & $P$ \\
\hline & .355 & 32.681 & & & \\
\hline \multicolumn{6}{|l|}{ Background Characteristics } \\
\hline Gender & & & .002 & .068 & .938 \\
\hline Age & & & .014 & .083 & .723 \\
\hline Education & & & -.056 & .071 & .067 \\
\hline \multicolumn{6}{|l|}{ Disease Variable } \\
\hline Disease Type & & & .201 & .084 & $.001 * *$ \\
\hline Duration of Illness & & & -.039 & .085 & .315 \\
\hline Duration of Treatment in & & & .066 & .097 & .090 \\
\hline \multicolumn{6}{|l|}{ Teaching Hospital } \\
\hline \multicolumn{6}{|l|}{ Coping Information } \\
\hline How to coping with symptoms & & & .190 & .037 & $.001 * *$ \\
\hline Control of discomfort and pain & & & .006 & .037 & .887 \\
\hline $\begin{array}{l}\text { Dealing with anxiety and } \\
\text { depression }\end{array}$ & & & .100 & .040 & $.032 * *$ \\
\hline $\begin{array}{l}\text { Dealing with fatigue and } \\
\text { tiredness }\end{array}$ & & & .124 & .040 & $.007 * *$ \\
\hline What to do in emergency & & & .103 & .037 & $.019 * *$ \\
\hline How others are coping & & & .080 & .032 & $.037 * *$ \\
\hline
\end{tabular}

Dependent variable - Self-efficacy at $\mathrm{P}<0.05$

$$
* \mathrm{P}<.001 \quad * * \text { Significant }
$$


Table 3 shows the coefficients and their significance levels. The overall model fit explain $36 \%$ of the variation on self-efficacy which was revealed to be statistically significant, $F(12,723)=$ 32.681, $\mathrm{p}<0.05$. An inspection of independent variables shows that patients' age (Beta $=.014$, $\mathrm{p}>0.05$ ), gender (Beta .002, $\mathrm{p}>0.05$ ) educational attainment (Beta $=-.056, \mathrm{p}>0.05)$, duration of illness $($ Beta $=-.039, \mathrm{p}>0.05)$ and duration of treatment $($ Beta $=.066, \mathrm{p}>0.05)$ are not significantly associated with patients' self-efficacy in managing chronic disease when other independent variables are held constant.

On the contrary, Table 3 shows that disease type (Beta $=.201, \mathrm{p}<0.05)$ is positively associated with self-efficacy when other variables are held constant. Access to health information on coping with symptoms $($ Beta $=.190, \mathrm{p}<0.05)$, coping with anxiety and depression $($ Beta $=.100, \mathrm{p}<0.05)$, coping with fatigue and tiredness (Beta $=.124, \mathrm{p}<0.05)$, coping with emergency $($ Beta $=.103, \mathrm{p}<0.05)$, and how others are coping $($ Beta $=.080, \mathrm{p}<0.05)$ are positively associated with self-efficacy in managing chronic diseases. Based on the significant associations found, the null hypotheses of no significant relationship between patient's access to coping information and patient's self- efficacy in managing chronic diseases based on the patient's personal characteristics is therefore rejected. Self -efficacy scores were related to disease type when other variables are held constant.

\section{Discussion}

\section{Level of self-efficacy and access to coping information for managing chronic diseases}

Findings of the study show that over half of the Seven hundred and eighty-four respondents have high or complete confidence that they can manage the symptoms, anxiety, fatigue, discomfort and pain of chronic illnesses, However, over twenty percent (>170 respondents) indicated that they had little or no confidence in managing these emotional challenges of living with their chronic illnesses. This indicates that they may not be coping effectively with the emotional aspect of their illnesses. This can be considered a high number considering that the issue is coping with health challenge which will enable the individual adapt to the illness for a better quality of life. This might not be unrelated to the findings of low access to coping information. 


\section{Relationship between Access to Coping Information and Patients' Self-Efficacy}

The study sought to determine if any relationship exist between patient' access to coping information and their self-efficacy in managing chronic illnesses. Findings from data analyzed showed all the variables of access to coping information were significantly $(\mathrm{p}<0.05)$ and positively correlated with self-efficacy. Higher level of access to coping information was moderately and lowly associated with higher patients' self-efficacy in managing chronic diseases. The finding suggests that health information access can contribute positively to developing patients' emotional and physical coping skills that are needed to counter the effects of chronic illnesses. Previous studies have also reported similar significant relationships between coping information and health outcome. Rubin, Peyrot, and Saudek (1993) examined the effects on emotional well-being and diabetes-related competence of an intensive education program taught by a multidisciplinary staff who taught diabetes-specific coping skills. The educational programme led to improvement on the measures of anxiety, self-esteem, and diabetes-specific knowledge and self-efficacy up to one year follow up. Also related to the present findings are the findings of Lode, Larsen, Bru, Klevan, Myhr and Nyland (2007) that patients with Multiple Sclerosis, who seem to cope more adequately with the disease, report that they received good information at the time of diagnosis.

\section{Disease and demographic variables, access to coping information and patients' self-efficacy in managing chronic diseases.}

Findings on multiple regression analysis computed for the association between disease and demographic variables, access to coping and self-efficacy, suggest that only disease type was the relevant independent variables that affect self-efficacy for coping with chronic diseases. This suggests that patients will develop coping skills when information is tailored to nature of their illnesses. On the contrary, age, gender, educational attainments were not associated with selfefficacy. Since disease type is related to self-efficacy, this suggests that patient with various chronic illnesses will have equal levels of self-efficacy in coping irrespective of their ages and gender when provided access to self-management information. Higher level of education does not predispose a patient to higher level of self-efficacy in coping when provided access to health. Duration of illness was also not significantly associated with self-efficacy in coping with their chronic illnesses. When patients have access to health information tailored to their illnesses, all 
will have the same level of self-efficacy irrespective of how long their illnesses had lasted. Some elements coping information were found to be associated with self-efficacy. These include information on coping with symptoms, anxiety and depression, fatigue, and how others are coping with their illnesses. Higher access to these health information items were found to be associated with higher levels of self-efficacy in managing chronic diseases. Considering that information for patient empowerment in self-care must be accurate and specific to the needs of the individual, the identified disease factors and health information that predict coping selfefficacy can be exploited when planning information delivery to patients for better access.

\section{Conclusions}

Findings of this study suggest that patients' access to coping information is positively and significantly correlated with self-efficacy in managing chronic diseases. The significant associations suggests that health information can enable patients develop requisite coping skills for successful living with chronic diseases. Therefore, health science librarians, health professionals, and other health information providers should ensure that patients are provided with access to health information in all areas of self-management. This will enable them cope successfully with chronic diseases. However, health information provision may need to be targeted to specific coping challenges for each chronic disease type.

\section{Recommendations}

The researcher recommends the following based on the findings of the research

1. The Federal Ministry of Health in Nigeria should institute an appraisal of health information disseminating structures in the teaching hospitals to ensure they exist, relevant and up-todate to meet the information needs of the new age health information users. They can establish national agencies that will coordinate patients' access to health information. These agencies will work to formulate, advocate and implement policies that ensure that people have access to needed health information to make right decisions on their care.

2. Hospital administrators and all stakeholders involved in health care should create an enabling environment for information sharing and flow to patients with chronic diseases by strategizing the use of health information in patient care. Health professionals can refer patients to information resources such as validated health sites on the Internet, patient support groups, and libraries where they can obtain more needed information. As a priority, patients 
at diagnosis should be provided with pamphlets, booklets, CD/DVD and audiovisual resources to enlighten patients on all aspects of self-care. These information resources should give explanation on the disease, symptoms, and how to cope with their symptoms. This information should be presented in the language the patient can comprehend

3. Library and information professionals in Nigeria should be play some roles in creating access to health information for patients with chronic diseases. Health science librarians can support patients by developing consumer health information collections and services in the library. Resources in the collection should include pamphlets, lay books, audiovisual resources etc. To ensure health science librarians play the expected role in providing access to health information, library schools in Nigeria can develop a specialist programme in medical librarianship. All the rudiments of health information service including consumer health information services should form part of the curriculum.

\section{Reference}

Ankem K. (2006). Factors influencing information needs among cancer patients: A metaanalysis Library \& Information Science Research, 28, 7-23. Retreved from https://www.sciencedirect.com/science/article/pii/S0740818805001234

Arora NK, Johnson P, Gustafson DH, McTavish F, Hawkins RP, \& Pingree S. (2002). Barriers to information access, perceived health competence, and psychosocial health outcomes: Test of a mediation model in a breast cancer sample. Patient Education and Counseling, 47, 37-46. Retrieved from https://www.pec-journal.com/article/S0738-3991(01)001707/fulltext

Bandura, A. (1997). Self-efficacy: The exercise of control. New York: Freeman.

Brashers, D. E, Goldsmith, D. J, \& Hsieh, E. (2002). Information seeking and avoiding in health contexts. Human Communication Research, 28, 258-71.Retrieved from https://onlinelibrary.wiley.com/doi/abs/10.1111/j.1468-2958.2002.tb00807.x

Centers for Disease Control and Prevention (CDC) (2017). Self-management education: Learn more. Feel better. Managing chronic conditions (any). Retrieved from https://www.cdc.gov/learnmorefeelbetter/sme/index.htm

Department of health and children (nd). Health Information: A National Strategy Retrieved from http://www.lenus.ie/hse/bitstream/10147/46713/1/1767.pdf 
Falvo, D. R. (2013) Psychosocial and functional aspects of chronic illness And disability in Medical and Psychosocial Aspects of Chronic Illness and Disability, Jones \& Bartlett Publishers, Burlington, MA. $5^{\text {th }}$ edition Retrieved from http://www.jblearning.com/samples/0763744611/4461_ch02_pass3.pdf

Institute of Medicine (2001) Crossing the Quality Chasm: A new health System for the 21st century, Washington, D.C.: National Academy Press. Retrieved from https://www.ncbi.nlm.nih.gov/books/NBK222274/

Lode, K. Larsen, J. P., Bru, E., Klevan, G., Myhr, K. M. \& Nyland, H. (2007). Patient information and coping styles in multiple sclerosis. Multiple Sclerosis, 13,792-799. Retrieved from http://journals.sagepub.com/doi/abs/10.1177/1352458506073482?journalCode=msja

Ma, C., Warren, J., Phillips, P. \& Stanek, J. (2006) Empowering patients with essential information and communication support in the context of diabetes. International Journal of Medical Informatics, 75, 577 - 596. Retrieved from https://www.sciencedirect.com/science/article/pii/S1386505605001784?via\%3Dihub

Miller, S. M. (1995). Monitoring versus Blunting Styles of Coping with Cancer Influence the Information Patients Want and Need about Their Disease implications for Cancer Screening and Management. Cancer, 76, 167-77.

Powers, M. A., Bardsley, J., Cypress, M., Duker, P., Funnell, M. M., Fischl, A. H., (2006). Vivian, E. Diabetes Self-management Education and Support in Type 2 Diabetes: A Joint Position Statement of the American Diabetes Association, the American Association of Diabetes Educators, and the Academy of Nutrition and Dietetics. Clinical Diabetes : A Publication of the American Diabetes Association, 2016, 34, 70-80. http://doi.org/10.2337/diaclin.34.2.70

Rubin R. R. and Peyrot, M. \& Saudek C. D. (1993). The Effect of a Diabetes Education Program Incorporating Coping Skills Training on Emotional Well-Being and Diabetes Self-Efficacy. The Diabetes Educator, 19, 210-214 http://journals.sagepub.com/doi/10.1177/014572179301900308

Snyder, C. R. (1999 ). Coping: The Psychology of What Works, Oxford: Oxford University Press.

Stanford Patient Education Research Center_Chronic Disease Self-efficacy scales. Retrieved from http:// patienteducation.stanford.edu

Tilly, J and Kulinski, K. (2017) Educating Adults about Chronic Disease Self-Management. Retrieved from 
http://www.eblcprograms.org/docs/pdfs/Educating_Adults_About_Chronic_Disease_Self -Management.pdf

Wood, R., \& Bandura, A., (1989). Social cognitive theory of organizational management. The Academy of Management Review, 14, 361-384. 